\title{
Rates and Routes of Hysterectomy for Benign Indications in Austria 2002-2014
}

\section{Hysterektomieraten und Zugangswege in Österreich 2002-2014}

Authors

Katharina Maria Edler ${ }^{1,2}$, Karl Tamussino ${ }^{1}$, Gerhard Fülöp ${ }^{3}$, Evi Reinstadler ${ }^{2}$, Walter Neunteufel ${ }^{2}$, Philipp Reif ${ }^{1}$, Rene Laky ${ }^{1}$, Thomas Aigmüller ${ }^{1}$

Affiliations

1 Department of Obstetrics \& Gynecology, Medical University of Graz, Graz, Austria

2 Department of Obstetrics \& Gynecology, Krankenhaus Dornbirn, Dornbirn, Austria

3 Gesundheit Österreich GmbH, Vienna, Austria

Key words

hysterectomy, hysterectomy rates, routes of hysterectomy, vaginal hysterectomy, minimally invasive hysterectomy, abdominal hysterectomy

\section{Schlüsselwörter}

Hysterektomie, Hysterektomieraten, operativer Zugangswege bei der Hysterektomie, vaginale Hysterektomie, minimalinvasive Hysterektomie, abdominale Hysterektomie

$\begin{array}{ll}\text { received } & 8.2 .2017 \\ \text { revised } & 27.3 .2017 \\ \text { accepted } & 30.3 .2017\end{array}$

Bibliography

DOI https://doi.org/10.1055/s-0043-107784

Geburtsh Frauenheilk 2017; 77: 482-486 @ Georg Thieme

Verlag KG Stuttgart · New York | ISSN 0016-5751

Correspondence

Karl Tamussino, MD

Department of Obstetrics \& Gynecology,

Medical University of Graz

Auenbruggerplatz 14, A-8036 Graz, Austria

karl.tamussino@medunigraz.at

\section{ABSTRACT}

Introduction Rates and routes of hysterectomy have implications for quality, costs and training. This study analyzed rates of benign hysterectomy and surgical approaches for benign hysterectomy in Austria from 2002 to 2014.

Material and Methods This was a population-based retrospective observational study of coding data from all acute care hospitals (public and private) in Austria. Main outcome measures were numbers of women undergoing hysterectomy for benign indications in Austria per year and the route of hysterectomy for benign indications.

Results The number of benign hysterectomies performed per year declined from 10675 in 2002 to 7747 in 2014, a decline of $27 \%$. The use of vaginal hysterectomy was stable ( $53 \%$ and $47 \%$, respectively). Use of laparoscopic techniques increased ( $5 \%$ in $2002,32 \%$ in 2014) whereas use of abdominal hysterectomy decreased ( $41 \%$ and $20 \%$, respectively).

Conclusions Numbers of benign hysterectomies performed per year in Austria declined substantially between 2002 and 2014. Use of vaginal hysterectomy was stable at about $50 \%$, whereas increased use of laparoscopic techniques was associated with lower rates of open hysterectomy.

\section{ZUSAMMENFASSUNG}

Einleitung Die Anzahl durchgeführter Hysterektomien und der gewählte operative Zugangsweg haben Implikationen für Qualität, Kosten und ärztliche Ausbildung. In dieser Studie wurden die Anzahl der in Österreich zwischen 2002 und 2014 durchgeführten benignen Hysterektomien und der gewählte operative Zugangsweg untersucht.

Material und Methoden Es handelt sich hier um eine retrospektive bevölkerungsbezogene Beobachtungsstudie basierend auf codierten Daten aus allen (öffentlichen und privaten) Akutkrankenhäusern in Österreich. Die wichtigsten Ergebnisse waren die jährliche Anzahl der Frauen in Österreich, die sich einer Hysterektomie für benigne Grunderkrankung unterzogen, sowie der gewählte operative Zugangsweg.

Ergebnisse Die Anzahl der jährlich durchgeführten Hysterektomien für benigne Erkrankungen ging von 10675 im Jahre 2002 zurück auf 7747 im Jahre 2014, was einem Rückgang von $27 \%$ entspricht. Der Anteil vaginaler Hysterektomien blieb relativ stabil (53\% resp. $47 \%$ ). Laparoskopische Methoden wurden zunehmend eingesetzt (5\% im Jahre 2002, 32\% im Jahre 2014), während der Anteil abdominaler Hysterektomien abgenommen hat (41\% resp. $20 \%$ ).

Schlussfolgerungen Die Anzahl der jährlich in Österreich für benigne Grunderkrankungen durchgeführten Hysterektomien ist zwischen 2002 und 2014 erheblich zurückgegangen. Der Anteil vaginaler Hysterektomien blieb stabil mit ca. $50 \%$, wohingegen der verstärkte Einsatz laparoskopischer Verfahren mit niedrigeren Raten von abdominalen Hysterektomien einherging. 


\section{Key Message}

Rates of benign hysterectomy in Austria per year declined by $27 \%$ between 2002 and 2014. Use of vaginal hysterectomy was stable at about $50 \%$; increased use of laparoscopic techniques was associated with lower rates of open hysterectomy.

\section{Introduction}

Hysterectomy is a common surgical procedure in women and most hysterectomies are performed for benign indications [1]. Hysterectomy rates vary considerably among regions and countries [2-12]. Medical and hormonal treatments (such as the levonorgestrel-releasing intrauterine device) and less invasive surgical options (such as endometrial ablations) have contributed to declining hysterectomy rates in numerous countries [2-12]. The subject of benign hysterectomy has received and continues to receive considerable attention in the medical literature and in the lay press [13-15]. In addition, hysterectomy can be done by various routes and with different technologies, and these have shifted and evolved over the years $[1,10,11]$. It is now widely agreed that hysterectomies should be performed by a minimally invasive approach, i.e., vaginally or laparoscopically, if possible. Furthermore, rates and routes of hysterectomy have implications for quality, costs and training.

We used a national database to analyse both hysterectomy rates and surgical routes for hysterectomy for benign indications in acute care hospitals in Austria between 2002 and 2014.

\section{Material and Methods}

Rates and routes of hysterectomy were analysed from data collated by the Austrian Ministry of Health and Women's Affairs, data evaluation was done by GÖG (Gesundheit Österreich $\mathrm{GmbH}$ ). The GÖG is a government agency with the mission to research, plan and coordinate healthcare in Austria. The data for the study derive from the Austrian DRG system (Diagnosen- und Leistungsdokumentation der österreichischen Krankenanstalten 2002-2014, DLD), which is used by all hospitals and therefore covers all inpatient treatments in both public and private hospitals in Austria. The DLD is a documentation system initiated in 1997 and is based on the ICD-10 coding system for diagnoses and so-called MEL codes (Medizinische Einzelleistung) for medical procedures. In 2002, this coding system was expanded to include the route of hysterectomy. The Austrian system has seven separate codes for hysterectomies: laparoscopic supracervical hysterectomy, total and laparoscopically assisted hysterectomy, abdominal hysterectomy, vaginal hysterectomy, radical laparoscopic hysterectomy, radical abdominal hysterectomy and radical vaginal hysterectomy.

We identified all inpatient stays in Austria with the intervention “Hysterectomy" from 2002 to 2014. MEL codes were linked to the coded diagnoses during the respective stay in order to ascertain which type of hysterectomy was done for which indication. Rates for hysterectomy for benign indications were calculated by subtracting hysterectomies performed for a malignant condition from

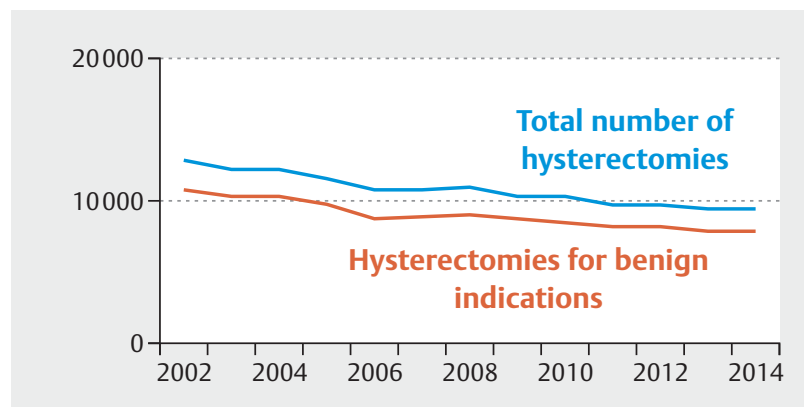

- Fig. 1 Numbers of hysterectomies (overall and for benign indications) in Austria 2002-2014. Source: MoHW - DLD 2002-2014; data evaluation by GÖG.

the overall number of hysterectomies. Hysterectomies coded for transgender patients were not included in the calculated rates per 100000 women, but are included in absolute numbers.

Age-adjusted rates were calculated as the number of inpatient stays with the intervention "Hysterectomy" per 100000 women referring to the mean European standard population 2013 obtained from Eurostat.

Because this was a secondary analysis of anonymized data, the protocol was not submitted to the institutional ethics committee.

\section{Results}

\section{Rates}

A total of 140329 hysterectomies were performed in acute care hospitals in Austria between 2002 and 2014. The overall number of hysterectomies per year declined steadily from 12764 in 2002 to 9501 in 2014. This is a decline of $25 \%$ - with 3263 fewer hysterectomies performed in 2014 than in 2002. The age-adjusted overall hysterectomy rate thus decreased from 316/100 000 women in 2002 to 206/100000 women in 2014.

Over the entire study period the large majority of hysterectomies were done for benign indications (84\% in 2002 and $82 \%$ in 2014; - Fig. 1). While the number of hysterectomies done for a malignant indication decreased by 16\% (2089 in 2002 vs. 1754 in 2014), the number of hysterectomies performed for benign indications decreased by $27 \%$ (10675 in 2002 vs. 7747 in 2014). The age-adjusted hysterectomy rate for benign indications decreased from 265/100000 in 2002 to 168/100 000 women in 2014.

Three indications accounted for $78 \%$ of the benign indications for hysterectomy: leiomyomas (42\%), pelvic organ prolapse $(25 \%)$ and abnormal uterine bleeding (11\%). Other benign indications included endometriosis, adenomyosis, chronic pelvic pain, cervical atypia, infections, benign tumors other than fibroids, and peripartal complications.

\section{Routes}

Minimally invasive techniques, specifically vaginal hysterectomy, were the most frequently used techniques for benign indications. In $2014,47 \%$ of benign hysterectomies were done vaginally, $23 \%$ laparoscopically, 20\% abdominally, and $9.3 \%$ as laparoscopic 


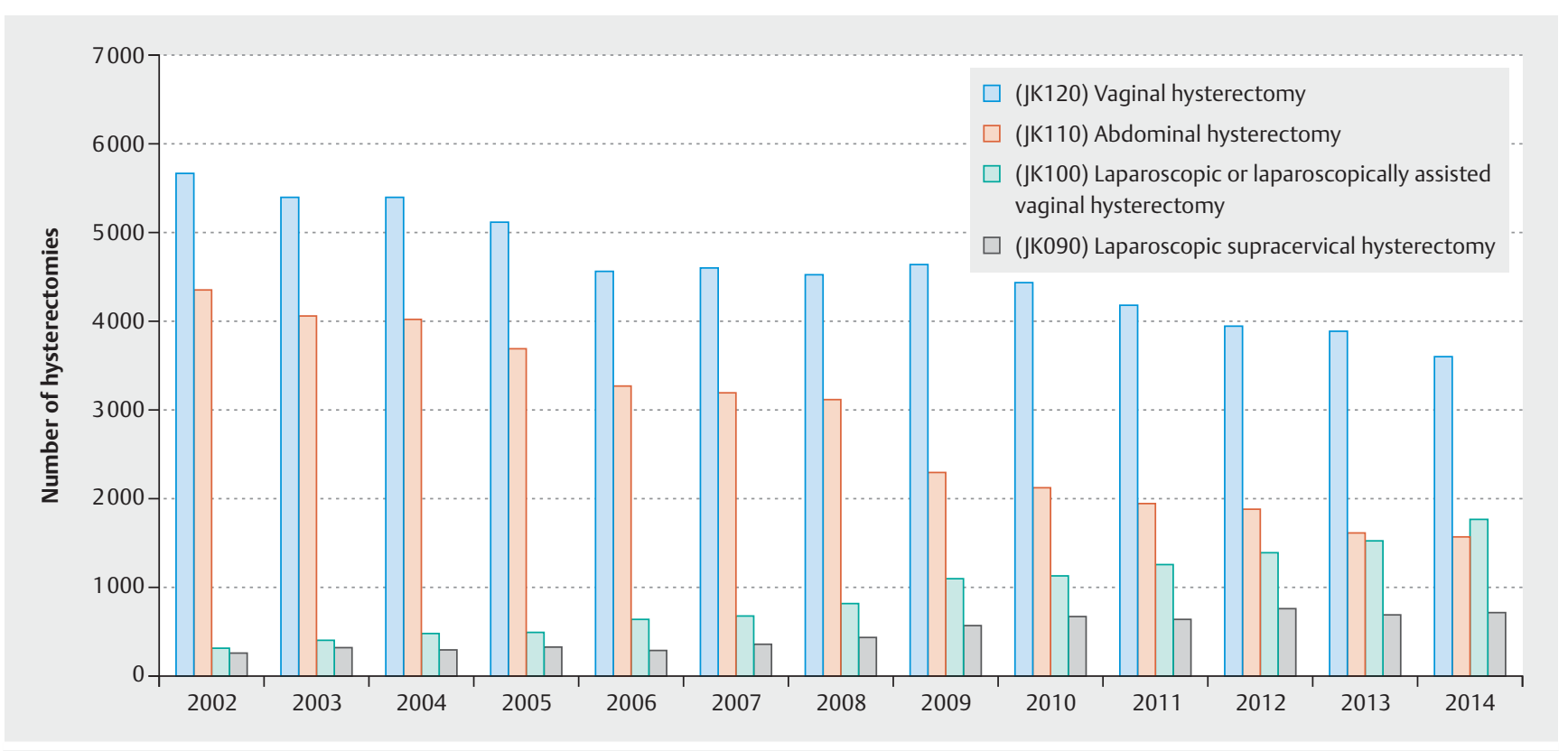

- Fig. 2 Routes of benign hysterectomy in Austria 2002-2014. Source: MoHW - DLD 2002-2014; data evaluation by GÖG.

supracervical hysterectomies; in 2002 the respective numbers were $53 \%, 3.1 \%, 41 \%$, and $2.5 \%$ ( Fig. 2 ). Thus, use of laparoscopic hysterectomy increased at the expense of abdominal hysterectomy, whereas the use of vaginal hysterectomy was near $50 \%$ in both time periods ( $\triangleright$ Fig. 2). Robotically-assisted hysterectomy is a rarity in Austria.

\section{Discussion}

Within the relatively brief period of 13 years, hysterectomy rates for benign indications in Austria fell by $27 \%$. This amounts to a major change in gynecologic practice. Regarding the routes of benign hysterectomy, laparoscopic approaches reduced the rate of abdominal hysterectomy from $41 \%$ to $20 \%$; the rate of vaginal hysterectomy was stable near $50 \%$.

A number of factors are likely to have contributed to the decline of benign hysterectomy in Austria. Less invasive treatment options - such as endometrial ablations, levonorgestrel-releasing intrauterine devices (introduced in Austria in 1997), other hormonal interventions, uterine artery embolization (UAE) - have been used increasingly to treat benign conditions such as abnormal uterine bleeding and fibroids. Also, it is likely that today neither women nor providers consider hysterectomy a first-line treatment for benign gynecologic conditions.

Declining hysterectomy rates in recent years have been reported from Australia [3], the Netherlands [9, 16], England [8, 21], Switzerland [4], Portugal [12], and Denmark [22]. In the USA, rate reductions of $36-39 \%$ in benign hysterectomies have been reported $[10,11]$.

Comparing hysterectomy rates amongst different countries is complicated by differences in data collection, definitions and doc- umentation as well as by different populations used for age-adjustment. With an overall hysterectomy rate of 207/100000 and a hysterectomy rate for benign indications of 168/100000 women in 2014, the hysterectomy rate in Austria is low compared to that reported from other countries ( $\triangleright$ Table $\mathbf{1}$ ).

The large variations in hysterectomy rates amongst countries with similar demographics imply that nonmedical factors influence the rates of hysterectomy. Specifics of local health care and reimbursement systems likely play a role, as do differences in attitude and clinical practice patterns [14-18].

In Austria, vaginal hysterectomy remains the most common approach to benign hysterectomy, with rates near 50\% through 2002 and 2014. The advance of laparoscopic surgery has increased the proportion of minimally invasive hysterectomies at the expense of abdominal hysterectomy (in Austria robotic hysterectomy is practically non-existent). This is consistent with efforts to increase the rate of minimally invasive approaches for hysterectomy for benign conditions.

There are remarkable variations in the use of different operation routes for benign hysterectomy amongst countries. In Western Australia 45\% [3], in France 58\% [19], in Germany 55\% [7], in Finland 44\% [20], and in the Netherlands 51\% [9], Portugal $21 \%$ [12], Denmark approximately $20 \%$ [22] of benign hysterectomies are performed by the vaginal route. In contrast, laparotomy is the preferred approach in the U.S. (54\% of inpatient hysterectomies [11]) and Sweden (63\%) [6]. Robotically-assisted hysterectomy, which accounted for $9.5 \%$ of all hysterectomies in the United States in 2010 [23], is practically non-existent in Austria.

Hysterectomy rates over time in the United States have been looked at by Wright et al. $[11,23]$ and more recently by Doll et al. [10]. Wright et al., analysing inpatient procedures, reported that the number of hysterectomies (including those done for cancer) 
- Table 1 Hysterectomy rates (and definitions) in different countries.

\begin{tabular}{|l|l|l|l|l|}
\hline Country & Authors & $\begin{array}{l}\text { Benign/ } \\
\text { malignant/total }\end{array}$ & Year & Hysterectomy rate \\
\hline Austria & Current study 2016 & Total & 2014 & $206 / 100000$ women \\
\hline Austria & Current study 2016 & Benign & 2014 & $167 / 100000$ women \\
\hline Germany & Stang 2011 & Total & $2005-2006$ & $362 / 100000$ person years \\
\hline Germany & Stang 2011 & Benign & $2005-2006$ & $295 / 100000$ person years \\
\hline Switzerland & Schweizer Gesundheitsobservatorium 2007 & Total & 2005 & $2.9 / 1000$ female residents \\
\hline USA & Whiteman 2008 & Total & 2003 & $5.1 / 1000$ women \\
\hline Western Australia & Spilsbury 2006 & Total & 2003 & $4.8 / 1000$ women years \\
\hline New Zealand & Scott 1995 & Total & 1991 & $365 / 100000$ women \\
\hline Sweden & Lundholm 2009 & Benign & 2003 & $210 / 100000$ women years \\
\hline Denmark & Gimbel 2001 & Total & 1998 & $182 / 100000$ women \\
\hline Netherlands & Hanstede 2012 & Benign & $1995-2005$ & 17.2 per 10 000 women \\
\hline Portugal & Gante et al. 2017 & Total & $2000-2014$ & 212 and $171 / 100000$ \\
\hline
\end{tabular}

performed annually decreased by $36 \%$ between 2002 and 2010 [11]. Abdominal hysterectomies accounted for $69 \%$ of procedures in 2002 , declining to $54 \%$ by 2010 ; the use of vaginal hysterectomy declined from 25 to $17 \%$ [11]. Use of laparoscopic hysterectomy declined from $15 \%$ in 2006 to $8.6 \%$ in 2010 , whereas use of robotic hysterectomy increased markedly, from 0.2 to $8.2 \%$ [ 11 , 23]. These figures did not include patients discharged on the day of surgery and thus probably underestimate the numbers of minimally invasive hysterectomies. Looking only at benign hysterectomies, Wright et al. reported an increase of the use of robotically-assisted hysterectomy from $0.5 \%$ in 2007 to $9.5 \%$ in 2010 [23]. In hospitals where robotic hysterectomies were done, robotic procedures accounted for over $22 \%$ of benign hysterectomies [23]. More recently, Doll et al. [10] reported that overall annual hysterectomy rates in commercially insured women decreased by 39\% from 2000 to 2014, and that in $201470 \%$ of benign hysterectomies were performed in an outpatient setting [10]. Doll et al. [10] did not report on routes of hysterectomy.

The reports from the U.S. by Wright et al. $[11,24]$ and Doll et al. [10] predate the morcellation debate that began in 2013 and led to an FDA safety communication on laparoscopic power morcellation in April 2014. Today, worries regarding morcellation of uteri containing unrecognized malignancy may influence decisions about the route of hysterectomy for presumed benign disease. In 2016 Harris et al. [24] looked at over 15000 benign hysterectomies in the Michigan Surgical Quality Collaborative before and after the FDA Communication in April 2014 and found a 4.1\% decrease in laparoscopic procedures and a commensurate increase in open and vaginal procedures. Similarly, a $5 \%$ increase in the rate of open hysterectomies was reported from the Kaiser Permanente system [25].

Reviews and guidelines consistently underline that vaginal hysterectomy, if feasible, is the method of choice concerning outcome and costs $[13,26-28]$. The comparatively high and stable rate of vaginal hysterectomy in Austria is encouraging in this regard.

The strengths of our study are the consistent acquisition of data over a 13-year time period in an entire (albeit small) country with a high-quality healthcare system and a strong tradition in gynecologic surgery and vaginal surgery in particular. Also, since all hysterectomies in Austria are performed on an inpatient basis (in contrast to the situation in the U.S. [10]), we captured virtually all procedures. Limitations are that coding may not always correct, though we consider major coding problems regarding benign vs. malignant procedures or the route of the procedures unlikely. Also, we have no data on complications because these data are not recorded centrally.

In conclusion, hysterectomy rates for benign indications in Austria declined by $27 \%$ in the 13 years between 2002 and 2014 . This is a major shift in clinical practice and has implications for costs and training. In the era of work-hour restrictions, the numbers of hysterectomies required in training and certification programs may not be realistic. Austria ranks among countries with low hysterectomy rates. The decline in benign hysterectomy rates is likely due to an increased use of conservative treatment options, both medical and surgical. The proportion of benign hysterectomies performed with a minimally invasive approach increased from $58 \%$ to $79 \%$, with an increase in laparoscopic hysterectomies seen at the expense of abdominal hysterectomies. This is encouraging and consistent with efforts to increase rates of minimally invasive approaches.

\section{Funding}

There was no external funding for this study. 


\section{Conflict of Interest}

None of the authors have competing interests relevant to this study.

\section{References}

[1] Falcone T, Walters MD. Hysterectomy for benign disease. Obstet Gynecol 2008; 111: 753-767

[2] Gimbel H, Settnes A, Tabor A. Hysterectomy on benign indication in Denmark 1988-1998. A register based trend analysis. Acta Obstet Gynecol Scand 2001; 80: 267-272

[3] Spilsbury K, Semmens J, Hammond I et al. Persistent high rates of hysterectomy in Western Australia: a population-based study of 83000 procedures over 23 years. BJOG 2006; 113: 804-809

[4] Schweizer Gesundheitsobservatorium. Hospitalisationsrate in somatischen Akutspitälern wegen Gebärmutterentfernung (Hysterektomie) pro 1000 Einwohnerinnen und Kaiserschnitt pro 1000 Geburten. Obsan November 2007 (Indikator 6.4.13)

[5] Whiteman MK, Hillis SD, Jamieson D] et al. Inpatient hysterectomy surveillance in the United States, 2000-2004. Am J Obstet Gynecol 2008; 198: 34.e1-34.e7

[6] Lundholm C, Forsgren C, Johansson AL et al. Hysterectomy on benign indications in Sweden 1987-2003: a nationwide trend analysis. Acta Obstet Gynecol Scand 2009; 88: 52-58

[7] Stang A, Merrill RM, Kuss O. Hysterectomy in Germany: a DRG-based nationwide analysis, 2005-2006. Dtsch Arztebl Int 2011; 108: 508-514

[8] Cromwell D, Mahmood T, Templeton A et al. Surgery for menorrhagia within English regions: variation in rates of endometrial ablation and hysterectomy. BJOG 2009; 116: 1373-1379

[9] Hanstede MM, Burger M], Timmermans A et al. Regional and temporal variation in hysterectomy rates and surgical routes for benign disease in the Netherlands. Acta Obstet Gynecol Scand 2012; 91: 220-225

[10] Doll KM, Dusetzina SB, Robinson W. Trends in inpatient and outpatient hysterectomy and oophorectomy rates among commercially insured women in the United States, 2000-2014. JAMA Surg 2016; 151: 876877

[11] Wright JD, Herzog TJ, Tsui J et al. Nationwide trends in the performance of inpatient hysterectomy in the United States. Obstet Gynecol 2013; 122: $233-241$

[12] Gante I, Medeiros-Borges C, Águas F. Hysterectomies in Portugal (20002014): what has changed? Eur J Obstet Gynecol Repod Biol 2017; 208: 97-102

[13] Aarts JWM, Nieboer TE, Johnson $\mathrm{N}$ et al. Surgical approach to hysterectomy for benign gynaecological disease. Cochrane Database Syst Rev 2015; (8): CD003677
[14] Domenighetti G, Casabianca A. Rate of hysterectomy is lower among female doctors and lawyers' wives. BMJ 1997; 314: 1417

[15] Domenighetti G, Luraschi P, Casabianca A et al. Effect of information campaign by the mass media on hysterectomy rates. Lancet 1988; 2 : 1470-1473

[16] Brölmann HA, Vervest HA, Heineman M]. Declining trend in major gynaecological surgery in The Netherlands during 1991-1998. Is there an impact on surgical skills and innovative ability? BJOG 2001; 108: 743748

[17] Hall RE, Cohen MM. Variations in hysterectomy rates in Ontario: does the indication matter? CMAJ 1994; 151: 1713-1719

[18] Jacobson GF, Shaber RE, Armstrong MA et al. Changes in rates of hysterectomy and uterus-conserving procedures for treatment of uterine leiomyoma. Am J Obstet Gynecol 2007; 196: 601.e1-601.e5

[19] David-Montefiore E, Rouzier R, Chapron C et al. Surgical routes and complications of hysterectomy for benign disorders: a prospective observational study in French university hospitals. Hum Reprod 2007; 22: 260265

[20] Brummer TH, Jalkanen J, Fraser J et al. FINHYST, a prospective study of 5279 hysterectomies: complications and their risk factors. Hum Reprod 2011; 26: 1741-1751

[21] Reid PC, Mukri F. Trends in number of hysterectomies performed in England for menorrhagia: examination of health episode statistics, 1989 to 2002-3. BM] 2005; 330: 938-939

[22] Topsoee MF, Ibfelt EH, Settnes A. The Danish hysterectomy and hysteroscopy database. Clin Epidemiol 2016; 8: 515-520

[23] Wright JD, Ananth CV, Lewin SN et al. Robotically assisted vs. laparoscopic hysterectomy among women with benign gynecologic disease. JAMA 2013; 309: 689-698

[24] Harris JA, Swenson CW, Uppal S et al. Practice patterns and postoperative complications before and after US Food and Drug Administration safety communication on power morcellation. Am J Obstet Gynecol 2016; 214: 98.e1-98.e13

[25] Saadat S, Arden D. How has the U.S. Food and Drug Administration morcellation warning affected rates of minimally invasive hysterectomy in a large multi-center managed care setting? [Abstract]. Am J Obstet Gynecol 2017; 216 (Suppl.): S572

[26] ACOG Committee Opinion No. 444: Choosing the route of hysterectomy for benign disease. Obstet Gynecol 2009; 114: 1156-1158

[27] Neis KJ, Zubke W, Römer T et al. Indications and route of hysterectomy for benign diseases - Guidelines of the DGGG, OEGGG and SGGG. Geburtsh Frauenheilk 2016; 76: 350-364

[28] Deffieux X, Rochambeau Bd, Chene G et al. Hysterectomy for benign disease: clinical practice guidelines from the French College of Obstetrics and Gynecology. Eur J Obstet Gynecol Reprod Biol 2016; 202: 83-91 